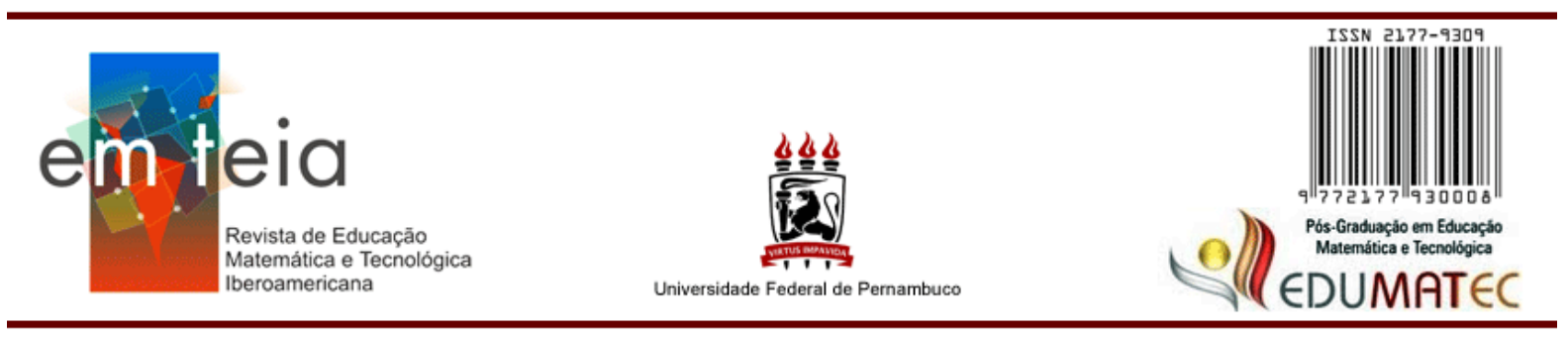

\title{
OS PROFESSORES E O USO DE TECNOLOGIAS DIGITAIS NAS AULAS REMOTAS EMERGENCIAIS, NO CONTEXTO DA PANDEMIA DA COVID-19 EM PERNAMBUCO
}

\author{
Nahara Morais Leite \\ Mestranda do PPGEdumatec \\ Universidade Federal de Pernambuco - Pernambuco - Brasil \\ nahara2503@gmail.com
}

Elidiene Gomes Oliveira de Lima

Mestranda do PPGEdumatec

Universidade Federal de Pernambuco - Pernambuco - Brasil

elidienegomes@hotmail.com

Ana Beatriz Gomes Carvalho

Doutora em Educação

Universidade Federal de Pernambuco - Pernambuco - Brasil

anabeatrizgpc@gmail.com

\section{Resumo}

Este artigo apresenta um estudo exploratório sobre a realidade dos professores de diversos níveis de ensino, com a suspensão das atividades presenciais provocada pela pandemia do COVID-19. O objetivo é analisar a formação e a atuação dos professores no contexto das aulas remotas, com a suspensão das atividades presenciais, durante a pandemia da COVID 19. O estudo é qualitativo e exploratório, com análise das respostas de 254 sujeitos de diferentes níveis e redes de ensino. A coleta foi realizada no segundo mês de isolamento social em Pernambuco e os resultados indicam que a falta de infraestrutura para a realização das atividades e a fragilidade na formação dos docentes para o uso das tecnologias digitais são os elementos apontados como grandes obstáculos no sucesso das aulas remotas.

Palavras-chaves: Formação; Educação; Inclusão Digital; COVID-19.

\section{Abstract}

This paper presents an exploratory study on the current scenario of teacher's reality at different levels of education with the suspension of classroom activities caused by the pandemic of COVID-19. The objective is analyzing the training and performance of teachers in the context of remote classes with the suspension of classroom activities during the COVID 19 pandemic. The study is qualitative and exploratory, with an analysis of the responses of 254 subjects from different levels and networks education. The collection was carried out in the second month of social isolation in Pernambuco and the 
results indicate that the lack of infrastructure to carry out the activities and the fragility in the teacher's training for digital technologies use are the elements pointed out as major obstacles in the success of remote classes.

Keywords: Formation; Education; Digital Inclusion; COVID-19.

\section{Introdução}

A existência de uma pandemia que atingiu todos os países e vem provocando milhares de mortes transformou radicalmente o cotidiano de estudantes e professores. O enfrentamento das questões sanitárias, com a indicação do isolamento social como única possibilidade de frear a disseminação do vírus, resultou na suspensão das aulas em todos os níveis e sistemas de ensino, não apenas no Brasil. Os países que insistiram na manutenção ou retomada das aulas presenciais, observaram a contaminação de grande parte da comunidade escolar. A incerteza sobre os efeitos da propagação da doença em espaços escolares, transformou a expectativa de uma suspensão temporária das aulas presenciais na incerteza de quando e como será possível retornar às aulas presenciais.

Atualmente, multiplicam-se textos, notícias e reportagens sobre a pandemia do COVID19 e suas consequências, principalmente no Sistema de Saúde. Entretanto, essa nova pandemia não afeta somente a saúde, mas também tem efeitos severos no sistema educacional. $\mathrm{O}$ isolamento social, uma das formas de combater o avanço da pandemia, criou novos hábitos e comportamentos na sociedade e, consequentemente, na Educação.

Ainda não sabemos se o ensino voltará a ser o mesmo no cenário pós-pandemia. Diversos docentes nos países afetados, inclusive no Brasil, estão trabalhando para se adaptar à nova rotina sem aulas presenciais, com o uso de recursos tecnológicos para a preparação de atividades que mantenham os alunos estimulados e, ao mesmo tempo, com disponibilidade para tirar as dúvidas. O Governo do Estado de Pernambuco adotou uma nova forma de continuar com as aulas, por meio do Ensino Remoto Emergencial (ERI, sigla em inglês) que está longe de ser o que se preconiza como Educação a Distância.

A decisão dos gestores em relação à adoção do ensino remoto está longe de ser um movimento dialogado com toda a comunidade escolar. Embora o tempo tenha evidenciado que a opção por aulas remotas foi a mais acertada, os conflitos iniciais com os professores foram inevitáveis, sobretudo porque as tensões provocadas pela pandemia e a dificuldade de adoção das tecnologias digitais, de forma quase instantânea, não apresentavam condições favoráveis. 
Consequentemente, a formação continuada é um assunto importante nesse período de pandemia, conforme Costa e Lins (2010), o qual fornece alternativas de trabalho para que os professores sejam levados a investigar o uso das tecnologias em sala de aula.

A adoção do ensino remoto, ainda que emergencial e provocado por fatores externos ao controle dos sistemas de ensino e da comunidade escolar, envolve uma série de elementos que estão em discussão há mais de duas décadas: a inclusão digital e a formação dos professores para o uso das tecnologias digitais, o letramento digital, a apropriação tecnológica, a aquisição de hardware e softwares, o acesso ao uso de tecnologias e até mesmo a qualidade e o custo da conexão. São temas intensamente abordados e pesquisados no Programa de Pós-Graduação em Educação Matemática e Tecnológica (Edumatec), da Universidade Federal de Pernambuco (UFPE), nos últimos dez anos, como veremos mais à frente.

O objetivo deste artigo foi o de analisar a formação e a atuação dos professores no contexto das aulas remotas, com a suspensão das atividades presenciais, durante a pandemia da COVID 19, em Pernambuco. O estudo é qualitativo e exploratório, com análise das respostas de 254 sujeitos, de diferentes níveis e redes de ensino, a um questionário online (Google Forms). A coleta foi realizada no segundo mês de isolamento social em Pernambuco e os resultados indicam que a falta de infraestrutura para a realização das atividades e a fragilidade na formação dos docentes para o uso das TDIC, na prática docente, são os grandes obstáculos ao sucesso das aulas remotas.

\section{A contribuição das pesquisas do PPGEDUMATEC da UFPE sobre os professores e o uso de tecnologias digitais}

A apresentação dos resultados das pesquisas desenvolvidas no âmbito do Programa de Pós-Graduação em Educação Matemática e Tecnológica, da Universidade Federal de Pernambuco, faz-se necessária neste artigo por duas razões: a similaridade no recorte territorial e temático. Como único Programa de Pós-Graduação, em Pernambuco, com uma linha específica de Educação Tecnológica, o programa apresenta produções de dissertações e teses que investigaram o uso de tecnologias digitais por professores da Educação Básica, em diversos sistemas educacionais de Pernambuco, e os resultados indicam alguns elementos para as discussões propostas neste artigo.

O levantamento das teses e dissertações no repositório Atena da Biblioteca Central da UFPE foi realizado em agosto de 2020. Foram encontradas 218 dissertações e 24 teses no banco de dados, desde 2014. Usando somente a palavra-chave "tecnologias digitais", foram 
encontradas 101 dissertações e 10 teses. Os resumos foram inseridos no software Atlas TI e foram selecionadas somente as dissertações e teses que atendessem aos seguintes critérios: uso de tecnologias digitais, como tema ou contexto de pesquisa, e investigação com professores, como sujeitos de pesquisa, no ensino presencial. Encontramos 13 dissertações e uma tese e os estudos apresentam resultados importantes para entendermos melhor a situação atual dos professores.

A tese de Bley (2018), "Panorama dos elementos influenciadores do processo da adoção de tecnologias por professores", verificou que o desafio são os professores desprovidos de um perfil inovador. Por isso, a adoção de tecnologia pelos professores deve alicerçar-se em uma política pública de formação, com documentos normativos que garantam um processo formativo reflexivo e inovador, com gestores de visão positiva da tecnologia e com uma equipe formadora qualificada e que busque inovar nas formações.

A pesquisa de Alves (2016), intitulada "O conflito cognitivo docente nas relações didáticas com a mesa educacional alfabeto", pesquisou o uso didático das mesas educacionais interativas nas escolas da rede municipal do Recife. Os resultados indicaram que o uso dessa prática tecnológica não foi efetivado, pois foi percebido que os docentes, ao se depararem com "novos elementos" em seu cenário didático, tiveram dificuldades que não foram superadas para a construção de uma prática tecnológica com a mesa alfabeto.

A pesquisa de Melo (2015), intitulada "O uso das tecnologias digitais na prática pedagógica: inovando pedagogicamente na sala de aula", foi realizada com 34 professores da Rede Pública Municipal de Olinda, das diversas áreas do Ensino Fundamental. Os resultados indicaram que os professores consideram a necessidade de cursos de formação que possibilitem ao docente vivenciar experiências que desenvolvam simultaneamente as capacidades técnicas, e, principalmente, as pedagógicas.

A pesquisa de Cunha (2017) intitulada “A prática pedagógica de professores do Instituto Federal de Pernambuco na qual se usam dispositivos móveis", pesquisou 13 professores e os resultados indicaram que os seus discursos e práticas evidenciam que os limites identificados não são para uma ausência de conhecimento dos dispositivos, como recursos na prática pedagógica, mas para a necessidade de uma maior intervenção pedagógica por parte da Instituição, para o desenvolvimento de formações que auxiliem a promover práticas pedagógicas inovadoras.

A pesquisa "Integração de tecnologias digitais na prática pedagógica: concepções de professores e de alunos do ensino médio", de Moreira (2015), analisou as concepções de 
professores e alunos do ensino médio acerca da integração das tecnologias digitais de informação e comunicação (TDIC) nas práticas pedagógicas. A autora identificou distanciamentos entre as concepções dos docentes e dos discentes e que, mesmo sem ter o apoio e a mediação necessária por parte dos professores, os alunos desenvolvem práticas significativamente produtivas, em relação as práticas de seus professores.

A pesquisa de Santos (2016), intitulada "O professor e as tecnologias digitais na educação de jovens e adultos: perspectivas, possibilidades e desafios", analisou as perspectivas, as possibilidades e os desafios que os professores do primeiro segmento da EJA, do município de Jaboatão dos Guararapes, apresentam para a inserção das tecnologias digitais em sua prática. Os resultados da pesquisa revelam que a inserção das tecnologias digitais na prática pedagógica da EJA não pode ser compreendida apenas como processo de instrumentalização do aluno, na perspectiva da inclusão digital.

A pesquisa de Espindola (2015), "Percepção docente sobre os indicadores de competência digital", buscou ouvir os docentes do Ensino Fundamental II e verificar a percepção destes quanto à competência digital para a docência e seus indicadores. A autora concluiu que a maioria dos professores aprova o uso de tecnologias na sala de aula e que alguns deles praticam ações que descrevemos na Matriz de Indicadores de Competência Digital, sendo possível constatar que aqueles que melhor aceitam a matriz são os que apresentam um conceito mais aprofundado para esta competência.

A pesquisa de Silva (2015), "Representações sociais de tecnologia compartilhadas pelos professores e suas relações com a prática pedagógica em função da região em que atuam”, analisou as representações sociais de tecnologia em sala de aula dos professores e suas relações com a prática pedagógica, identificando os elementos constitutivos e nucleares dessas representações e analisando se há diferenças entre as representações sociais de tecnologia dos professores de Recife e do interior de Pernambuco. A pesquisa analisou as representações sociais de 457 docentes de escolas públicas da rede municipal e estadual, distribuídos no estado de Pernambuco, e os resultados indicam que a relação desse saber com a prática pedagógica está atrelada à região que atuam, com distanciamentos entre as regiões. A faixa etária também foi determinante para o resultado.

A pesquisa de Santos (2015), “As mídias sociais estão na moda? Efemeridade e apropriação das mídias sociais como recursos pedagógicos”, afirma que a efemeridade tem situado alunos e professores em níveis diferentes de letramento digital e apropriação tecnológica, fazendo com que exista uma grande dificuldade na apropriação de Mídias Sociais, 
enquanto recursos pedagógicos que contribuam efetivamente nas relações de ensino e aprendizagem.

A pesquisa de Silva (2014), "Formação continuada de professores e tecnologia: concepções docentes, possibilidades e desafios do uso das tecnologias digitais na educação básica", indicou que os docentes concebem possibilidades de aprendizagem com uso das TDIC, numa perspectiva progressista, porém, os desafios referentes à formação continuada, infraestrutura e o tempo pedagógico dificultam o uso das TDIC como instrumento mediador no processo de ensino e aprendizagem, numa perspectiva progressista. Para a autora, é difícil para os professores integrarem as tecnologias na sua prática docente, sem mudança da cultura escolar. A mudança das concepções dos docentes não é suficiente para promover a aprendizagem dos estudantes com uso das tecnologias, se a cultura escolar continuar conservadora.

O trabalho de Carmo (2014), "Planejamento de Aula no "Espaço da Aula" do Portal do Professor do MEC por Alunos de Pedagogia: Uma questão de inclusão digital docente?”, concluiu que a inclusão digital docente não ocorre apenas com o conhecimento da técnica, possibilidades de acesso e uso da Internet e redes sociais, mas, sobretudo, por meio do conhecimento didático-pedagógico.

Queiroz (2014) em sua pesquisa “O uso de mídias por professores egressos do Programa de Formação Continuada Mídias na Educação" concluiu que, em relação à integração das mídias de modo crítico e na perspectiva da produção e autoria, a proposta do Curso Mídias na Educação não se efetivou.

A pesquisa de Silva (2014), "O ensino de estratégias de leitura no Programa Aluno Conectado: o caso de um docente de Língua Portuguesa", concluiu que a falta de conectividade e de conhecimento do material disponibilizado nos tablets, entre outras questões, fizeram com que o professor não usasse adequadamente o tablet em favor do ensino e da aprendizagem da leitura.

Silva (2012), com a pesquisa "Travessia Reflexiva do Silêncio/Diálogo Interior: a construção do professor no contexto da cibercultura", concluiu que a implementação do PROUCA nas escolas não trouxe contribuições significativas para instigar a reflexão do professor e para sua inclusão digital e a dos alunos, o que, em parte, se deve às lacunas apresentadas pelo programa (formação de professores, falta de suporte técnico e pedagógico, bem como o funcionamento do computador), o que remete à inclusão subalterna. 
A pesquisa de Procrifka (2012), "Inclusão Digital nas Políticas Públicas para Formação de Professores em Pernambuco", concluiu que os programas de política pública de inclusão digital do professor não promovem o uso das tecnologias no contexto pedagógico, isto é, não estabelecem políticas de formação ou orientação para os professores beneficiados, resultando em poucas mudanças no processo de inclusão digital dos docentes em sala de aula.

Os resultados das pesquisas apresentadas aqui mostram que os cenários pesquisados desde 2012 não foram substancialmente alterados e que as lacunas apontadas não foram sanadas com as ações de políticas públicas para o incremento do uso das tecnologias digitais, nas salas de aula da Educação Básica. E possível identificar as fragilidades apontadas nas pesquisas, nos resultados obtidos no atual contexto das aulas remotas, como veremos no tópico das análises.

\section{A inclusão digital na formação dos docentes}

A inserção de tecnologias digitais nas escolas públicas brasileiras é realizada por meio de políticas públicas, principalmente na aquisição de equipamentos e na formação continuada dos professores. Por isso, a inclusão digital, em uma sociedade socialmente desigual, deve considerar questões culturais, diferentes níveis de apropriação tecnológica e condições sociais. De acordo com Warschauer (2006) e Cazeloto (2008), a inclusão digital somente terá sentido se promover a inclusão social.

Uma questão importante a ser destacada é a desigualdade gigantesca entre os sistemas públicos e privados da Educação Básica e a própria distância social entre as famílias dos estudantes brasileiros. Enquanto alunos de escola particular aprendem por meio de recursos tecnológicos, como vídeos ao vivo ou gravados, muitos estudantes de escolas públicas sequer têm acesso a internet. Além disso, nem todos os municípios brasileiros possuem estruturas tecnológicas para ofertar o ensino remoto proposto pelo Governo, e nem os professores têm a formação adequada para dar aulas virtuais.

Segundo Kenski (2008), a melhoria da qualidade de ensino e aprendizagem vai além dos investimentos de recursos tecnológicos na escola. É importante oferecer uma estrutura com permanentes formações para que os professores possam inseri-los em seu planejamento de forma mais confortável. Para Carvalho e Alves (2018), a complexidade e a diversidade de elementos que influenciam os resultados da inclusão digital na escola indicam a necessidade de mais pesquisas aprofundadas com outros contextos, promovendo benefícios para os alunos, família e comunidade. Logo, o caminho é a "formação continuada de professores ser concebida como uma ferramenta capaz de ampliar os horizontes teóricos e metodológicos, indo além de 
questões internas das instituições de ensino e entendendo a conjuntura social" (FERREIRA, 2018).

Referente à essas novas formas de aprender e ensinar no contexto da formação tecnológica do professor, registramos a citação de Pimenta (1997) no documento da Prefeitura do Recife que discorre sobre a autoformação do professor:

[...] pensar sua formação significa pensá-la como um continuum de formação inicial e contínua. Entende, também, que a formação é, na verdade, autoformação, uma vez que os professores reelaboram os saberes iniciais em confronto com suas experiências práticas, cotidianamente vivenciadas nos contextos escolares (PIMENTA, 1997, p. 56 apud RECIFE, 2015a, p. 36).

No documento oficial, a concepção de autoformação profissional do professor é entendida como uma forma de construção de saberes voltado para sua área de atuação de forma autônoma, para buscar constantemente maneiras de como ajudar, compreender e melhor atuar no seu campo de trabalho facilitando as soluções dos desafios encontrados na escola.

A integração dos recursos tecnológicos às atividades pedagógicas desenvolvidas nas escolas é permeada por diversos aspectos que envolvem o cotidiano escolar, desafiando a direção, a coordenação pedagógica e, principalmente, os professores e as professoras regentes:

A garantia da disponibilidade de infraestrutura adequada, a organização da dinâmica escolar, as condições para a realização do planejamento didático e para a formação continuada no uso das tecnologias na educação são questões que precisam ser refletidas, discutidas e planejadas nas unidades educacionais (RECIFE, 2015b, p. 58).

É necessário urgência na formação dos docentes, além das estruturas fundamentais garantidas, no processo educativo, para a promoção da dinâmica escolar, de forma mais qualitativa e significativa, melhorando a qualidade no ensino dos professores e nas aprendizagens dos estudantes com o uso dos recursos tecnológicos.

\section{Recentes pesquisas sobre a COVID-19 na Educação}

Atualmente, têm surgido vários estudos relacionados à suspensão das aulas presenciais, devido à pandemia do novo COVID-19. Os governos de diferentes países recorreram ao ensino remoto para o retorno às aulas. Essa mudança exigiu uma adaptação rápida, principalmente, por parte dos professores. 
Segundo dados da Revista Educação, mais de 1,5 bilhão de alunos e 60,3 milhões de professores de 165 países foram afetados pelo fechamento das escolas, devido à pandemia da COVID-19. Nessa crise de proporção global, educadores e famílias tiveram que lidar com a imprevisibilidade, (re)aprendendo a ensinar com apoio das tecnologias. Por exemplo, na China, cerca de 240 milhões de crianças e jovens se adaptaram rapidamente ao fechamento das instituições de ensino e passaram a ter aulas remotas em uma escala jamais vista, da Educação Básica ao Ensino Superior.

No Brasil, alguns institutos e empresas privadas vêm realizando pesquisas que são replicadas pela mídia tradicional, muitas vezes, sem a análise crítica necessária. Uma das pesquisas recentemente produzida pelo Instituto Península identificou como os professores estão se organizando após a suspensão das aulas e o início do trabalho remoto. A pesquisa ressalta que os professores estão abertos a continuar estudando, mesmo nesse caos. Entre os 2.400 respondentes da pesquisa estão professores da Educação Básica, das redes privadas e públicas, desde a educação infantil até o ensino médio, incluindo diferentes modalidades como o EJA (Educação de Jovens e Adultos).

Um dos principais resultados encontrados é o papel das secretarias de educação que são agentes fundamentais na definição de recursos que serão usados para que a Educação continue acontecendo e, inclusive, alcance os alunos com diferentes acessos à internet. A suspensão das aulas é uma medida comum às três redes presentes no estudo (privada, estadual e municipal). Entretanto, a rede particular mostra estar mais preparada para o momento, representado $65,3 \%$ dos respondentes de escolas particulares que afirmam prestar suporte a distância para os alunos, contra $14,1 \%$ da rede municipal e 36,2\% da estadual. Esses dados indicam a existência da desigualdade entre as condições de enfrentamento da pandemia, com as aulas remotas, nos diferentes sistemas. Além da esperada diferença entre as escolas públicas e particulares, observa-se uma fragilidade maior ainda no sistema municipal.

E uma pesquisa em andamento recentemente lançada pela UNESCO, em apoio a iniciativa da cátedra da UNESCO em Formação de Professores e do Departamento de Pesquisas Educacionais da Fundação Carlos Chagas (FCC), que está coordenando um estudo com o objetivo de entender como professores brasileiros, que atuam nas redes públicas e privadas, estão realizando suas atividades docentes, neste momento de isolamento social, e suas expectativas para o período pós-pandemia, por meio de um questionário online.

Considerando o contexto de enfrentamento da pandemia e a urgência na construção de possíveis cenários para a Educação, apresentaremos a seguir os resultados da pesquisa realizada 
pelo grupo de pesquisa com professores de diferentes níveis e redes de ensino sobre o período de suspensão das atividades presenciais.

\section{Percurso metodológico}

O objetivo deste artigo foi analisar a formação e a atuação dos professores no contexto das aulas remotas com a suspensão das atividades presenciais, durante a pandemia da COVID 19. O estudo é qualitativo e exploratório, com análise das respostas de 254 sujeitos de diferentes níveis e redes de ensino. A coleta foi realizada no segundo mês de isolamento social em Pernambuco, entre os dias 13 de Maio e 4 de Junho de 2020, como proposta de investigação do grupo de pesquisa, em uma ação de enfrentamento do cenário da pandemia em Pernambuco, onde todas as aulas, em todos os níveis e esferas de ensino, foram suspensas desde o dia 16 de março. Os sujeitos da pesquisa foram professores de diferentes níveis e redes de ensino, contactados através de meio eletrônico com a indicação de gestores das respectivas redes. Analisamos os diferentes níveis, redes, tempo de experiência em sala de aula e área do conhecimento, em um universo de 254 docentes.

A abrangência dos níveis e redes de ensino foi compensada com o recorte geográfico: os professores contactados como sujeitos de pesquisa trabalham em Pernambuco, na capital e na região metropolitana, uma das áreas mais afetadas do país com a pandemia do COVID-19, provocando a suspensão de todas as atividades nas instituições educacionais, públicas e privadas, desde o dia 16 de março. O estudo foi realizado com o formulário Google Forms contendo 30 questões, com perguntas objetivas e subjetivas. Selecionamos as questões relacionadas com o perfil dos professores da Educação Básica e as condições para o uso das tecnologias digitais com as aulas remotas.

\section{Análise e discussão dos dados}

Em relação ao perfil dos participantes e o nível de escolaridade, os dados mostram que nenhum participante possui Magistério Médio. Tivemos 10,2\% com ensino superior completo e $2 \%$ cursando outra graduação; $31,1 \%$ com especialização; $15,7 \%$ com mestrado concluído, enquanto 6,3\% estão cursando. Com Doutorado, tivemos 28,7\% com o curso concluído e 5,5\% com o curso em andamento. Em relação à amostra do nível de ensino em que os docentes atuam, observamos que há professores que atuam em mais de um nível de ensino: 20,9\% dos docentes atuam nos anos iniciais da Educação Básica, aproximadamente 22,4\% nos anos finais, 35,4\% no Ensino Médio/Técnico e 42,1\% no Ensino Superior. 
Entre esses professores entrevistados, $85,4 \%$ dos docentes já usavam algum tipo de tecnologia digital para uso pessoal, antes da pandemia da COVID-19; 11,8\% s afirmaram que utilizavam, às vezes; e 2,8\% não utilizavam. Os dados indicam que a maioria dos docentes conheciam e já usavam as tecnologias digitais em seu uso pessoal. Entretanto, temos um percentual de docentes que afirmaram não utilizar nenhuma tecnologia digital com frequência para o seu uso pessoal, e isso é bastante preocupante, se consideramos que vivemos no contexto da cultura digital.

Podemos observar as dificuldades dos professores quando relacionamos os dados do uso das tecnologias digitais para uso pedagógico com o seu uso pessoal. Antes da pandemia, 54,7\% afirmaram que as utilizavam em sua prática pedagógica; 14,6\% afirmaram que não utilizavam: e $30,7 \%$ afirmaram que às vezes. Apenas metade dos professores utilizavam as tecnologias digitais em sua prática pedagógica presencial, reforçando os resultados encontrados nas pesquisas de Procrifka (2012) e Silva (2012). Segundo Almeida (2000), é possível analisar a introdução da tecnologia na escola de uma forma que seja mais um recurso, isto é, um mediador cultural.

Quando questionados sobre as interfaces digitais que dominavam, a predominância, acima de 50\%, foi de Google Meet, YouTube, Facebook, Instagram, e-mail, Whatsapp, Moodle, Jitsy e Skype. Percebemos aqui que o domínio dos professores está relacionado com o uso de redes sociais, e não necessariamente com o resultado de processos formativos realizados anteriormente, confirmando o resultado de pesquisa de Santos (2015). A única plataforma de aprendizagem que surgiu entre as opções mais destacadas na pesquisa foi o Moodle e, provavelmente, isso está relacionado ao uso dos professores como cursistas nas ofertas de formação das redes de ensino. Embora esse resultado indique a formação dos professores em relação ao uso das tecnologias digitais, ainda é um uso muito restrito. Considerando o contexto do ensino emergencial remoto, as redes sociais podem ser usadas como recursos que estimulam o interesse dos alunos, promovendo o compartilhamento de informações e comunicações, desenvolvendo trabalhos colaborativos e permitindo ao aluno participar dos processos de ensino e aprendizagem.

Quando questionamos se o docente recebeu alguma forma de orientação/treinamento para realizar suas atividades remotas, $42,1 \%$ deles responderam que sim e 57,9\% que não. Esses dados ressaltam a importância da formação continuada e o despreparo dos sistemas para fornecer alternativas de trabalho, bem como o suporte teórico necessário. Esses dados contradizem as pesquisas sobre a formação continuada para o uso de tecnologias digitais 
oferecida pelos sistemas de ensino, identificadas nos trabalhos de Melo (2015), Queiroz (2014), Silva (2014) e Procrifka (2015). Esse conflito de informações pode ocorrer por dois motivos: os professores não identificam os processos de formação continuada como elementos que os preparariam para esse momento ou os professores não se se apropriaram do uso das tecnologias digitais, consolidando o seu letramento digital.

No questionamento para saber se o docente buscou alguma orientação/treinamento externa para melhorar o seu trabalho com as tecnologias digitais, podemos observar que $75,2 \%$ dos professores afirmaram que sim e 24,8\% que não. Esse dado é muito importante, pois indica que o professor foi obrigado a buscar outras alternativas para desenvolver as competências e habilidades necessárias para atuar no cenário de aulas remotas.

Perguntamos também como o professor se autoavalia em relação ao manuseio das tecnologias, no caso de ligar e desligar equipamento, sanar pequenos problemas de áudio, de recepção de sinal, entre outros. 55,9\% dos professores afirmaram apresentar facilidade; 13,8\% afirmaram ter muita facilidade; $28,3 \%$ afirmaram dificuldade; $2 \%$, com muita dificuldade.

Dentre os problemas apontados pelos professores na realização das aulas remotas, no contexto da pandemia, as mais relevantes (considerando que era possível escolher mais de uma opção) foram que $86,1 \%$ declararam ser a falta de domínio do professor com as tecnologias; $80,6 \%$ concordaram ser a formação para o desenvolvimento de atividades remotas; $80,2 \%$ afirmaram ser a estrutura em casa, no que se refere aos equipamentos, conexões, organização familiar; $65,1 \%$ responderam que falta material adequado para o desenvolvimento de atividades remotas; 48,4\% afirmaram ser a sobrecarga de trabalho, sem a remuneração adequada; $22,6 \%$ apontaram que o ensino remoto não é eficiente; e 23\% afirmaram que não há poder decisório na construção de alternativas para as aulas remotas.

Esses dados ressaltam que a falta de equipamentos, acesso à internet, formação dos docentes e estruturas são pontos cruciais para se realizar um ensino remoto emergencial proposto pelos sistemas de ensino e instituições privadas. Um dos problemas que foi identificado nos resultados tem relação com a desigualdade social, principalmente entre escolas públicas e particulares. Além desses elementos, é possível identificar, na opção falta de domínio com as tecnologias, a confirmação dos resultados das pesquisas de Bley (2018), Espindola (2015), Alves (2016) e Cunha (2017). 


\section{Considerações finais}

Ao analisar o cenário dos docentes com o uso das tecnologias digitais em aulas remotas, durante período de pandemia da COVID-19, foram consideradas as informações que não apenas descrevessem esse cenário, mas também as relações com as pesquisas acadêmicas na área. Os resultados evidenciaram que aproximadamente $60 \%$ dos professores ainda não recebeu formação para orientação e treinamento visando realizar atividades remotas e que $80 \%$ não considera que as ações de formação continuada para o uso pedagógico das tecnologias digitais fossem úteis para esse momento. No entanto, observa-se um esforço por parte dos docentes, pois cerca de $70 \%$ deles buscou alguma orientação/treinamento externo para melhorar o seu trabalho com as TDIC.

Examinando o enfrentamento do docente em aulas remotas, durante a pandemia da COVID 19, em aulas não presenciais, muitos professores concordaram que precisam ter mais domínio com as tecnologias e, para que isso ocorra, é preciso formação para o desenvolvimento de atividades remotas, desconsiderando qualquer processo de formação anterior. Outro fator a se considerar é a falta de estrutura e material adequado para o desenvolvimento de atividades remotas em casa, além da sobrecarga de trabalho para planejar aulas adaptadas ao Ensino Remoto. Muitos professores afirmam que necessitam ter uma remuneração adequada, outros não cogitam a ideia de que Ensino Remoto pode favorecer o processo educativo e nem vem como alternativa para retorno das aulas, o que é bastante preocupante considerando que as aulas remotas possam se estender por muito mais tempo do que foi previsto inicialmente.

Diante desse cenário, independente dos questionamentos sobre a qualidade ou quantidade de formações realizadas, percebemos que há urgência na formação dos docentes. Além disso, é preciso garantir as estruturas necessárias para o processo educativo, possibilitando formas mais qualitativas e significativas no processo de ensino e aprendizagem, com o uso dos recursos tecnológicos. Silva (2017, p. 42) considera que "ensinar, agora, para além do conteúdo, é estar conectado, a esta nova realidade. Surge, então, uma nova cultura, que ocupa nosso lar, nosso trabalho, a vida das pessoas".

A pesquisa indicou que a garantia de infraestrutura adequada para a organização do processo educativo em seus planejamentos didáticos e para a formação continuada na inclusão das tecnologias digitais são questões que precisam ser refletidas, discutidas e necessitam de mais esforços para garantir a qualidade do ensino e aprendizagem. Além dos investimentos nas instituições privadas e públicas, é essencial nesse momento fortalecer a parceria com a família, 
formar vínculos com a educação para o enfrentamento do contexto das aulas remotas durante a pandemia da COVID 19.

\section{Referências}

ALMEIDA, Maria E. Informática e formação de professores. Secretária de Educação e Distância. Brasília: Ministério da Educação, 2000.

COSTA, Marília L. C. da; LINS, Abigail F. Trabalho colaborativo e utilização das tecnologias da informação e comunicação na formação do professor de Matemática. Educação Matemática Pesquisa, São Paulo, v. 2, n. 3, p. 452-470, 2010.

CARVALHO, Ana Beatriz; ALVES, Thelma Panerai. Cultura digital e formação docente: o desenvolvimento de competências digitais para a sala de aula no contexto da sociedade em rede. In: SILVA, Adriana M. Paulo; FREIRE, Eleta (Orgs.). Pesquisas e práticas formativas: diálogos sobre a formação docente. Recife: Editora UFPE, 2018.

CAZELOTO, Edilson. Inclusão Digital: uma visão crítica. São Paulo: SENAC, 2008.

FERREIRA, Á e Lima; GOMES, A. V. da Silva; BRAGA, B. P.; BARACHO, L. C. A.; VIEIRA, M. C. L. de. BRITO, M. C. C.; MACHADO, Y. S. R. Sala de aula invertida: Uma proposta de inovação metodológica na formação de professores. Anais do III Congresso sobre Tecnologias na Educação, Fortaleza, 2018.

RECIFE. Secretaria de Educação. Política de Ensino da Rede Municipal do Recife: ensino fundamental do $1^{\circ}$ ao $9^{\circ}$ ano / organização: Jacira Maria L'Amour Barreto de Barros, Katia Marcelina de Souza, Élia de Fátima Lopes Maçaira, 2015a. 372 p.: il. (Política de Ensino da Rede Municipal do Recife, v. 3)

RECIFE. Secretaria de Educação. Política de ensino: Tecnologias na Educação / organização: Jacira Maria L’Amour Barreto de Barros, Élia de Fátima Lopes Maçaira, Katia Marcelina de Souza. - Recife: Secretaria de Educação, 2015. 84 p.: il. (Política de Ensino da Rede Municipal do Recife, v. 5). 2015b

SILVA, Ricardo. Construção de indicadores para gestão de tecnologia de informação e comunicação na educação: um Estudo de Caso. 2017. Tese (Doutorado) - Programa de Pósgraduação em Educação Matemática e Tecnologia, Centro de Educação, Universidade Federal de Pernambuco, 2017.

WARSCHAUER, Mark. Tecnologia e inclusão social: A exclusão digital em debate. São Paulo: Editora Senac São Paulo, 2006. 214 p.

XAVIER, Carmélia Regina Silva; MAIA, Dennys Leite. Desenvolvimento Profissional, Tecnologia Digital e Conceitos Estatísticos na Formação de Professores que Ensinam Matemática. In: CONGRESSO SOBRE TECNOLOGIAS NA EDUCAÇÃO (CTRL+E), 4, 
2019, Recife. Anais do IV Congresso sobre Tecnologias na Educação. Porto Alegre: Sociedade Brasileira de Computação, dec. 2019 . p. 202-211. 